\title{
Collision tumor of bone: primary chondrosarcoma of bone as a rare recipient of tumor-to-tumor metastasis from metastatic breast carcinoma
}

\author{
Wesley S. Greer ${ }^{1}$, Jerad M. Gardner ${ }^{2}$, Corey O. Montgomery ${ }^{1}$ \\ 1. Department of Orthopaedic Surgery, University of Arkansas for Medical Sciences, Little Rock, USA. 2. Department of \\ Pathology, University of Arkansas for Medical Sciences, Little Rock, USA.
}

Correspondence: Wesley S. Greer. Address: 4301 W Markham St, Slot 531, Little Rock, USA. E-mail:

wsgreer@uams.edu

Received: May 19, 2015

Accepted: J une 19, 2015

Online Published: July 10, 2015

DOI : $10.5430 /$ crcp.v2n4p25

URL: http://dx.doi.org/10.5430/crcp.v2n4p25

\begin{abstract}
Collision tumors are the rare phenomenon of two histologically distinct tumors occurring in the same anatomic location. We report an unusual case of metastatic breast carcinoma colliding with primary grade 1 chondrosarcoma in the femur of a 58-year-old female.
\end{abstract}

\section{Key words}

Collision tumor, Chondrosarcoma, Breast carcinoma, Bone metastasis, Tumor to tumor metastasis

\section{I ntroduction}

Collision tumors represent the rare phenomenon in which two or more distinct and unrelated tumors reside concurrently in one location as either both primary tumors ${ }^{[1]}$, one primary and one metastatic tumor (also known as "tumor to tumor metastasis") ${ }^{[2]}$ or both metastatic tumors ${ }^{[3]}$. We report an unusual case of a collision tumor involving metastatic breast adenocarcinoma and primary grade 1 chondrosarcoma occurring in the femur of a 58-year-old female patient.

\section{Case presentation}

A 58-year-old female was referred to our institution for evaluation of a distal femoral shaft lesion. She had a history of inflammatory breast cancer (Stage IIIB) that was diagnosed and treated in 2007 but had recently recurred with development of a malignant pleural effusion found in 2014. She had a several week history of progressive femoral pain and discomfort. On physical examination, tenderness was noted in the area of the lesion but no palpable mass could be felt. Range of motion of the knee was limited and painful.

Radiographs demonstrate an $8 \mathrm{~cm} \times 3 \mathrm{~cm}$ lesion in the distal femur with intralesional calcifications and endosteal scalloping (see Figure 1). An MRI of the femur revealed a heterogeneous lobulated lesion with medial wall cortical thinning/erosion with surrounding soft-tissue edema (see Figure 2). Both the plain films and MRI findings were concerning for chondrosarcoma. 
Figure 1. AP (1A) and lateral (1B) $x$-ray views of the right femur demonstrate a distal femoral shaft bone lesion in the intramedullary canal with a focus of dense stippled calcification, measuring approximately $8 \mathrm{~cm} \times 3 \mathrm{~cm}$, along with medial cortical wall erosion.

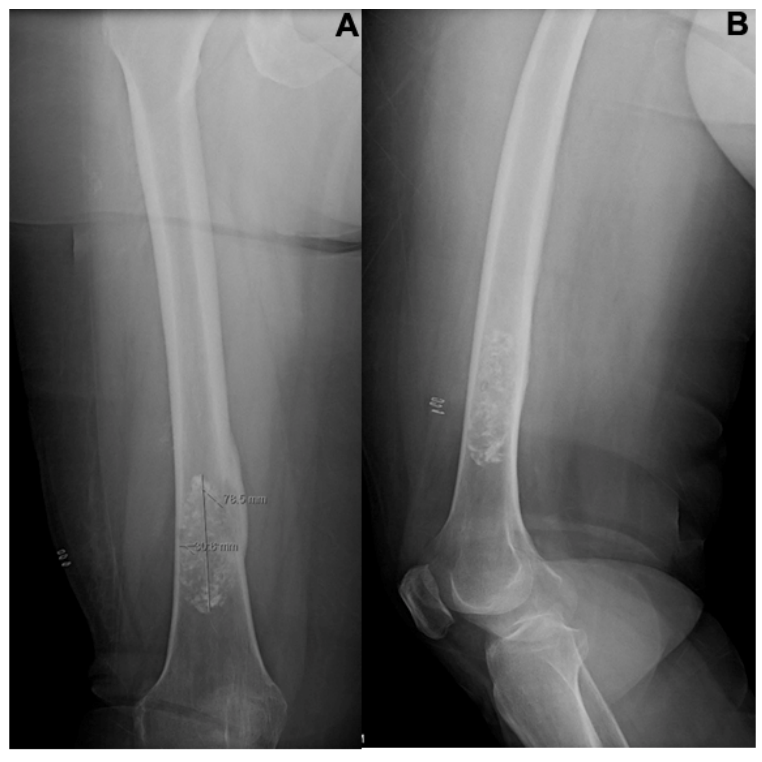

Figure 2. Coronal $\mathrm{T} 1$ and $\mathrm{T} 2 \mathrm{MRI}$ views of the right femur. T1 images (2A) demonstrate a low signal intensity mass with associated medial cortical wall thinning. T2 images (2B) demonstrate a higher signal intensity with intralesional heterogeneity consist with a cartilage neoplasm. No overt cortical wall erosion or soft-tissue mass was noted.

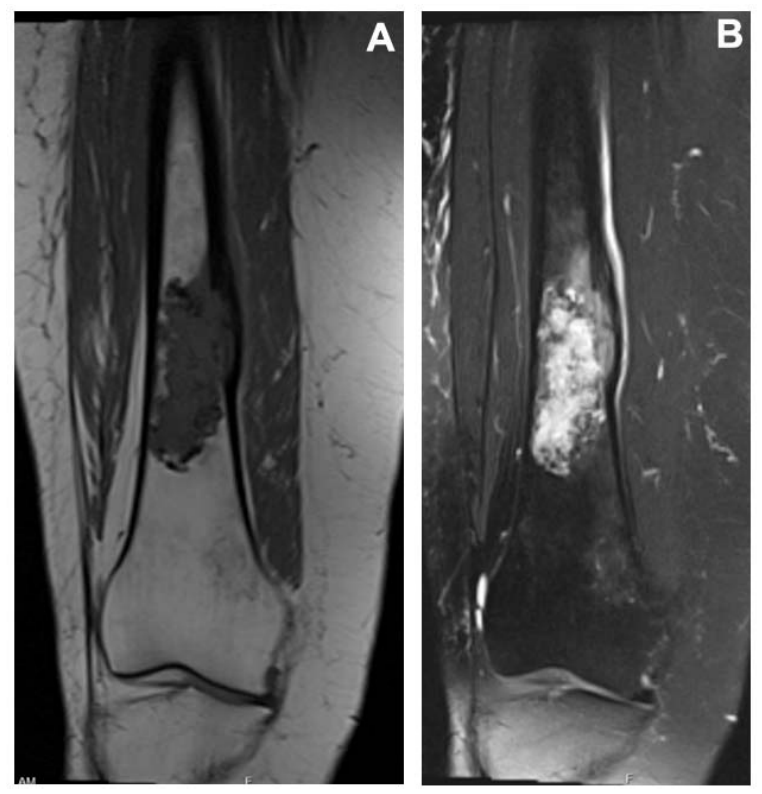

A whole body bone scan (see Figure 3) was performed showing uptake in the lumbar spine, ribs, and the femoral shaft. An open biopsy of the distal femur lesion was performed and was histologically consistent with a grade 1 chondrosarcoma. After discussion with the patient, she underwent an intralesional curettage with placement of bone cement along with plate and screw fixation for treatment. Final pathology on this curettage specimen displays grade 1 chondrosarcoma as well as metastatic breast adenocarcinoma directly adjacent to the chondrosarcoma (see Figure 4).

\section{Discussion}

There are many descriptions in the literature of various colliding tumors presenting in a wide range of anatomic locations. Some of the many locations of development include the skin ${ }^{[4]}$, stomach ${ }^{[5]}$, kidney ${ }^{[6]}$, bladder ${ }^{[7]}$ and brain ${ }^{[8]}$. Not only have collision tumors been documented to arise in various anatomic locations, but they have been documented to arise as both benign tumors ${ }^{[9]}$, benign/malignant tumors ${ }^{[7]}$ and both malignant tumors ${ }^{[5]}$. Also, collision tumors primarily consist of two colliding tumors, but rare collision tumors consisting of three tumors have been described in the skin ${ }^{[10,12]}$ and uterus ${ }^{[11]}$ as well. 
Figure 3. Multiple areas of osseous uptake in the thoracolumbar spine and right distal femoral shaft are seen on bone scan
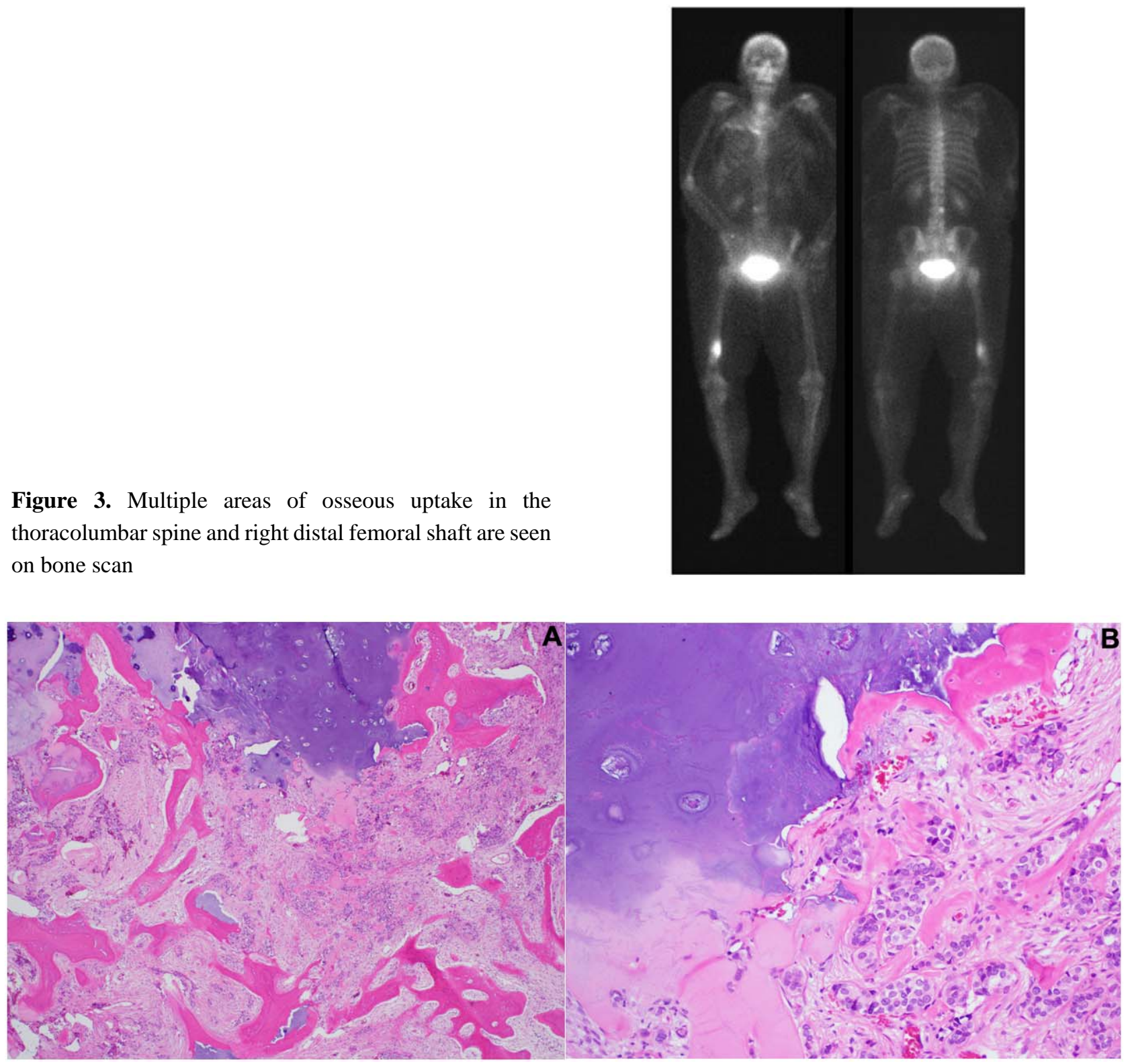

Figure 4. On low power examination (4A), blue nodules of relatively mature cartilage are seen at the top of the field with adjacent pink islands of reactive bone formation. In the center of the field are numerous small nests of metastatic carcinoma with extensive background fibrosis and desmoplasia (H\&E stain; 40× magnification). Higher power (4B) clearly displays chondrosarcoma (upper left) directly abutting the small infiltrative nests of metastatic breast adenocarcinoma (lower right) (H\&E stain; 200× magnification).

Collision tumors when involving the bone are relatively rare and have not been described involving more than two tumors. When discussing primarily osseous collision tumors, Smith et al. reported three cases of osteosarcoma developing adjacent to enchondroma ${ }^{[13]}$. Sanerkin et al. reported six cases of high grade osseous sarcomas arising next to enchondroma ${ }^{[14]}$. More recently, Galvin et al. reported one case of metastatic carcinoma to an enchondroma ${ }^{[15]}$. Our literature review identified only one other report of a metastatic adenocarcinoma colliding with chondrosarcoma: this was a collision tumor consisting of grade 1 chondrosarcoma and metastatic adenocarcinoma presenting in the scapula ${ }^{[16]}$.

Before making a diagnosis of a collision tumor between a carcinoma and a sarcoma histologically, the possibility of sarcomatoid carcinoma must first be excluded. Sarcomatoid carcinoma is a form of poorly differentiated carcinoma in 
which all or part of the tumor is composed of malignant spindle cells resembling a sarcoma. The sarcomatous component may sometimes resemble specific histologic subtypes of sarcoma, including osteosarcoma and chondrosarcoma (socalled "heterologous differentiation"). Unlike the well differentiated cartilage present in our case, the chondrosarcomatous component of a sarcomatoid carcinoma would typically be markedly atypical and high grade histologically. Additionally, the known history of widely metastatic breast carcinoma and absence of any history of a primary sarcomatoid carcinoma elsewhere in this patient are further findings that strongly argue against the possibility sarcomatoid carcinoma in our patient.

Chondrosarcoma is a malignant cartilage tumor which can occur as a primary tumor or as a secondary tumor arising from a pre-existing benign cartilage neoplasm. Pain, which is uncommon in benign enchondromas, is often a presenting complaint in both low and high grade chondrosarcoma. Radiographically, chondrosarcoma typically demonstrates endosteal scalloping, cortical disruption, and extension into adjacent soft tissue, features that help distinguish it from benign cartilage tumors ${ }^{[17]}$. Dedifferentiated chondrosarcoma occurs when a high grade undifferentiated-appearing (non-cartilaginous) sarcoma arises out of an adjacent typical chondrosarcoma ${ }^{[17]}$.

Low grade cartilaginous neoplasms are notoriously difficult to diagnose by histologic features only, as grade 1 chondrosarcoma can have histologic features nearly identical to enchondroma. Clinical and radiographic correlation are essential in distinguishing between these two entities. In our patient, the radiographic and MRI findings were more suggestive of chondrosarcoma than enchondroma. The treatment options for low grade chondrosarcoma include intralesional curettage, adjuvant therapy (argon beam) and cementation, or wide excision ${ }^{[18]}$. Plate fixation is sometimes added when osseous large voids are present after intralesional curettage. Metastatic carcinoma was only identified in the curettage specimen in our patient and was not present in the initial biopsy. However, as intralesional curettage with adjuvant therapy and cementation has been demonstrated to be an effective treatment for osseous metastatic disease, this unexpected finding in the curettage specimen did not alter our surgical management of the patient ${ }^{[19]}$.

\section{References}

[1] Abdelwahab IF, Klein MJ, Kenan S, et al. Coexistence of primary bone tumours: report of 4 cases of collision tumours. Can Assoc Radiol J. 2002; 53(5): 296-302. PMid: 12500382.

[2] Fried BM. Metastatic Inoculation of a Meningioma by Cancer Cells from a Bronchiogenic Carcinoma. Am J Pathol. 1930; 6: 47-52. PMid: 19969886.

[3] Vyas M, Menon S, Desai SB. Collision tumor of kidney: A case of renal cell carcinoma with metastases of prostatic adenocarcinoma. Indian J Med Paediatr Oncol. 2013 Jan; 34(1): 21-3. PMid: 23878482. http://dx.doi.org/10.4103/0971-5851.113409

[4] Dueber JC, Coffin CM. Collision of chronic lymphocytic leukemia/small lymphocytic lymphoma and melanoma. Blood. 2013 Jun 13; 121(24): 4819. PMid: 23923507. http://dx.doi.org/10.1182/blood-2012-12-473181

[5] Unal B, Elpek GO, Gelen T, et al. Gastric collision tumor: Case report of a rare adenocarcinoma and a typical carcinoid tumor. Oncol Lett. 2013 Jul; 6(1): 212-214. PMid: 23946806.

[6] Sella A, Ro JY. Renal cell cancer: best recipient of tumor-to-tumor metastasis. Urology. 1987 Jul; 30(1): 35-8. http://dx.doi.org/10.1016/0090-4295(87)90568-1

[7] Anani W, Amin M, Pantanowitz L, et al. A series of collision tumors in the genitourinary tract with a review of the literature. Pathol Res Pract. 2014 Apr; 210(4): 217-23. PMid: 24447800. http://dx.doi.org/10.1016/j.prp.2013.12.005

[8] Jin G, Hao S, Xie J, et al. Collision tumors of the sella: coexistence of pituitary adenoma and craniopharyngioma in the sellar region. World J Surg Oncol. 2013 Aug 7; 11: 178. PMid: 23919255. http://dx.doi.org/10.1186/1477-7819-11-178

[9] Gross BC, Carlson ML, Driscoll CL, et al. Collision tumor of the facial nerve: a synchronous seventh nerve schwannoma and neurofibroma. Otol Neurotol. 2012 Oct; 33(8): 1426-9. PMid: 22975907. http://dx.doi.org/10.1097/MAO.0b013e31826a52aa

[10] Bloom BS, Kamino H, Hale CS, et al. Collision tumor of eccrine poroma, seborrheic keratosis, and a viral wart. Dermatol Online J. 2014 Dec 16; 20(12). PMid: 25526344.

[11] Jang KS, Lee WM, Kim YJ, et al. Collision of three histologically distinct endometrial cancers of the uterus. J Korean Med Sci. 2012 Jan; 27(1): 89-92. PMid: 22219620. http://dx.doi.org/10.3346/jkms.2012.27.1.89 
[12] Cornejo KM, Deng AC. Malignant melanoma within squamous cell carcinoma and basal cell carcinoma: is it a combined or collision tumor?--a case report and review of the literature. Am J Dermatopathol. 2013 Apr; 35(2): 226-34. PMid: 22588546. http://dx.doi.org/10.1097/DAD.0b013e3182545e27

[13] Smith GD, Chalmers J, McQueen MM. Osteosarcoma Arising in Relation to an Enchondroma: A report of 3 cases. J Bone Joint Surg Br. 1986; 68(2): 315-9. PMid: 3457012.

[14] Sanerkin NG, Woods CG. Fibrosarcomata and Malignant Fibrous Histiocytomata Arising in Relation to Enchondromata. J Bone Joint Surg Br. 1979; 61-B(3): 366-72. PMid: 225333.

[15] Galvin DH, Hornstein AM, Levine SM, et al. Collision of a metastatic carcinoma to an enchondroma. Orthopedics. 2000; 23(12): 1281-4. PMid: 11144497.

[16] Yildirim M, Sayın A, Oztop F, et al. Collision Tumor of the Scapula: A Case Report. The Internet Journal of Surgery [Internet]. 2008 [Cited 2015 May 18]; 17(2). PMid: 11029557.

[17] Marco RA, Gitelis S, Brebach GT, et al. Cartilage Tumors: Evaluation and Treatment. J Am Acad Orthop Surg. 2000 ; 8: $292-304$.

[18] Aarons C, Potter BK, Adams SC, et al. Extended intralesional treatment versus resection of low-grade chondrosarcomas. Clin Orthop Relat Res. 2009; 467(8): 2105-2111. PMid: 19142690. http://dx.doi.org/10.1007/s11999-008-0691-8

[19] Bickels J, Dadia S, Lidar Z. Surgical Management of Metastatic Bone Disease. J Bone Joint Surg Am. 2009; 91: 1503-1516. PMid: 19487532. http://dx.doi.org/10.2106/JBJS.H.00175 